\title{
Depletion of trace elements and acute ocular toxicity induced by desferrioxamine in patients with thalassaemia
}

\author{
S DE VIRGILIIS, M CONGIA, M P TURCO, F FRAU, C DESSI, F ARGIOLU, R SORCINELLI, \\ A SITZIA,* AND A CAO
}

Istituto di Clinica e Biologia dell Eta' Evolutiva, Universita' Studi Cagliari, and *Istituto di Clinica Oculistica, Universita' Studi Cagliari, Cagliari, Sardinia, Italy

SUMMARY High doses of intravenous desferrioxamine infused over a short period of time induce a large faecal and urinary iron excretion but also produce retinal abnormalities that are characterised by decreased amplitude on electroretinography and defective dark adaptation. This regimen also results in high faecal iron, zinc, and copper excretion, and reduced granulocyte zinc concentrations and alkaline phosphatase activity. The retinal abnormalities may be related to the zinc and copper deficiency and/or iron depletion 'per se' which interferes negatively with critical iron dependent enzymes.

Subcutaneous infusion of desferrioxamine is the most efficient method for reducing the iron burden in patients with thalassaemia major who are transfusion dependent. ${ }^{1-6}$ The daily infusion of 40 $60 \mathrm{mg} / \mathrm{kg}$ over 12 hours for six days a week is usually sufficient to obtain iron balance. ${ }^{1-4}$ Because some patients fail to comply with this regimen the additional administration of large doses by intravenous infusion has been proposed. ${ }^{3}$ High doses of desferrioxamine, either by intravenous or subcutaneous administration, however, may result in optic neuropathy or high frequency sensorineural hearing loss, or both. ${ }^{78}$ Likewise, in rabbits anaesthetised with urethane, the intravenous infusion of large doses of desferrioxamine produced a reversible reduction in the amplitude of the electroretinogram. ${ }^{9}$ Toxic concentrations are probably reached when the dose of desferrioxamine administered is disproportionately high in relation to the amount of iron available for chelation. In these conditions desferrioxamine may chelate critical trace elements such as copper and zinc, ${ }^{10}$ the depletion of these elements may be responsible for the neurotoxic effect of the drug.

In this study we monitored the development of ocular abnormalities and possible zinc or copper depletion, or both, in a group of patients with thalassaemia major who were chelated with desferrioxamine by a combination of traditional daily subcutaneous infusion and monthly intravenous administration of large doses because of failure to comply with the regimen of subcutaneous administration.

\section{Patients and methods}

Fifteen children, aged from 9 to 16 years, with transfusion dependent thalassaemia major and moderate iron overload (serum ferritin concentrations from 1100 to $2000 \mu \mathrm{g} / \mathrm{l})$, because of low compliance with daily infusion of subcutaneous desferrioxamine, were treated by a combination of traditional daily subcutaneous infusion and monthly intravenous administration of very large doses according to a previously published scheme. ${ }^{11}$ Each patient was treated for 10 consecutive months but the balance study (see later) was carried out only once.

The dose of desferrioxamine for subcutaneous infusion was $40-60 \mathrm{mg} / \mathrm{kg}$ over a period of 12 hours each night for six days a week. The intravenous infusion was given over a period of 24 hours at the dosage of $10-12 \mathrm{~g}(200-450 \mathrm{mg} / \mathrm{kg})$ dissolved in $750 \mathrm{ml}$ of $5 \%$ glucose solution. Urinary and faecal iron concentrations, zinc and copper excretion, serum zinc pattern, leukocyte zinc concentrations, and alkaline phosphatase activities were analysed only once, as detailed later, before and after the infusion of intravenous desferrioxamine when we introduced the combination of both intravenous and subcutaneous administration. 
Ophthalmic evaluation was also carried out before and after the termination of the infusion, but this assessment was repeated from two to three times at times of successive intravenous infusion and again one, two, and three months after we interrupted the intravenous infusions while continuing the subcutaneous administration.

\section{OPHTHALMOLOGIC ASSESSMENT}

The ophthalmic assessment included determination of the best corrected visual acuity by standard methods, pupillary reaction, ocular motility, slit lamp examination for changes in the anterior segment, and visual field measurement on a calibrated Goldman kinetic perimeter with light intensity regulated at 31.5 apostilb. A decrease above $20 \%$ in the average peripheral extent of the field in at least two quadrants was considered abnormal. Adapted electroretinograms were obtained according to $\mathrm{Babel}^{12}$ with flashes of white light of constant colour range and intensity of 2 joule, 1 hertz/second at $30 \mathrm{~cm}$ from ocular plane (Pantops 200-Ferlux Instruments). The amplitudes of the response were considered abnormal when the value was decreased more than $20 \%$ from normal values (190 (SD15) $\mu \mathrm{V}$ ). During dark adaptation, after a preliminary light adaptation, we noted the stage at which the amplitude of the slow scotopic positive wave (the scotopic components of the electroretinogram are mainly due to the activity of the rods in dark adaptation) reached that of the photopic component. This is referred to as the 'transition phenomenon,' which is a valuable sign for the judgment of the scotopic function. ${ }^{13}$

\section{METABOLIC STUDIES}

In order to carry out copper, zinc, and iron balance studies each patient was admitted to the hospital for a week. With the aim of eliminating any residual effect of the subcutaneous infusion the day before admission the daily infusion of subcutaneous desferrioxamine was interrupted. While in the hospital the patients were on a strict controlled diet containing roughly $8-10 \mathrm{mg} /$ day iron, $0.1 \mathrm{mg}$ copper $/ \mathrm{kg}$ body weight, and 0.3-0.4 mg zinc/ $\mathrm{kg}$ body weight. Diet and collection of the urine and stool were carefully controlled by nurses who were specifically instructed to avoid any faecal contamination with urine. Collection periods of stools were defined by administering radio-opaque markers.

Precautions against environmental contamination were taken for all diet, blood, urine, and stool collections and analyses. Specimens were stored only in plastic containers and only low mineral content water and ultra high purity reagents were used in sample and standards preparation; before use, all glassware and plastic containers were acid washed in $1.0 \mathrm{~N}$ hydrochloric acid for 30 minutes and rinsed six times in deionised water.

Blood samples from peripheral veins were collected with plastic syringes and stainless steel needles and put into plastic tubes. Serum and granulocyte zinc concentrations and granulocyte alkaline phosphatase activity were measured in samples taken before and at the end of the intravenous infusion as well as one month later.

Basal iron, zinc, and copper excretion were evaluated in urine and faeces collected for three days before the infusion of desferrioxamine. The effect of this infusion was determined by measuring these elements in the urine and faeces collected on the day of the infusion as well as three days after. During this study period the subcutaneous infusion was interrupted.

An aliquot of the preinfusion and postinfusion urinary pools was prepared and frozen for further analysis. The faeces were homogenised with a known amount of deionised water. An aliquot was removed and dried at $100^{\circ} \mathrm{C}$ overnight and then ashed in a muffle furnace at $550^{\circ} \mathrm{C}$ and left overnight. The resultant ash was dissolved with $10 \%$ hydrochloric acid, transferred to a volumetric flask, and made up to volume with demineralised water.

Serum, urinary, and faecal iron, zinc, and copper were determined by atomic absorption (IL 551 Spectrophotometer). Granulocyte alkaline phosphatase activity was assayed with p-nitrophenylphosphate as substrate according to It-Koon and Moss. ${ }^{14}$ Granulocytes were separated from the other blood cells according to Boyum. ${ }^{15}$ The specimens used for the analysis contained a percentage of granulocytes varying from 90 to $100 \%$. Statistical analysis was carried out by Student's paired $t$ test.

\section{Results}

\section{OPHTHALMOLOGIC EVALUATION}

Visual acuity and average field size were normal in all subjects. No isolated field defect (scotomata) or enlargement of the blind spot were detected. Fundoscopy showed no pigment abnormalities, focal lesions, macular oedema, or unusual vascular patterns. In three patients the electroretinograms showed a decreased amplitude before and at the end of the desferrioxamine infusions as well as at follow up examinations carried out at one, two, and three months later. Seven patients, who had a normal electroretinogram before the infusion, showed a decreased amplitude at the evaluation carried out when the infusion was terminated. The same pattern was recorded at least twice at each successive infusion. In these subjects a normal 


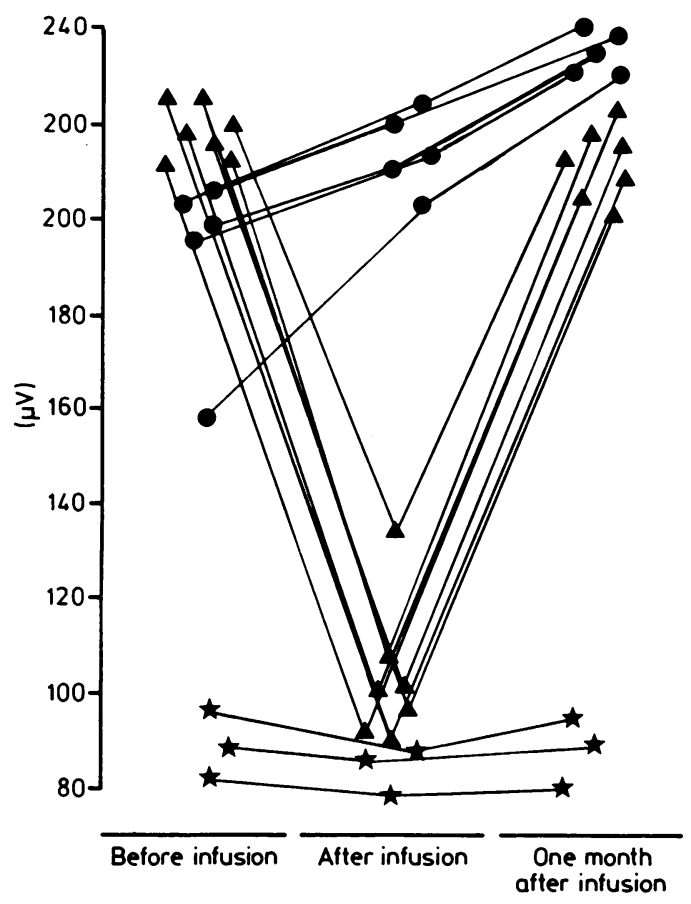

Fig 1 Effect of intravenous infusion of desferrioxamine on the amplitude on electroretinography. Patients with normal amplitude (О); patients with transitory decreased amplitude $(\mathbf{\Delta})$; and patients with persistent decreased amplitude ( $\star$ ). electroretinogram was seen at follow up examination after the termination of intravenous treatment (fig 1).

In the three patients with permanent abnormalities shown on their electroretinograms and in six out of the seven with the transient effects we noted when control measurements were taken immediately after infusion of intravenous desferrioxamine a 'transition phenomenon' appeared after 14 to 18 minutes in the dark. In our age matched controls this phenomenon occurred from a minimum of 8 to a maximum of 10 minutes. The remaining five patients did not show any abnormalities of their electroretinograms.

\section{METABOLIC STUDIES}

Fig 2 shows the effect of the intravenous infusion of desferrioxamine on serum zinc concentrations. The patients were divided into three groups: those with no retinal abnormalities, those who showed a decreased amplitude on an electoretinogram after infusion of desferrioxamine, and those with permanent abnormalities shown on an electroretinogram. During the 24 hours of the infusion all serum zinc concentrations fell to within the normal ranges $(84.2$ (SD 12) $\mu \mathrm{g} \%(12.9(1.8) \mu \mathrm{mol} / \mathrm{l}))$. During this period fluctuations in zinc concentrations occurred with peak concentrations in the morning and the lowest concentrations in the afternoon. No significant differences in the zinc concentrations or the

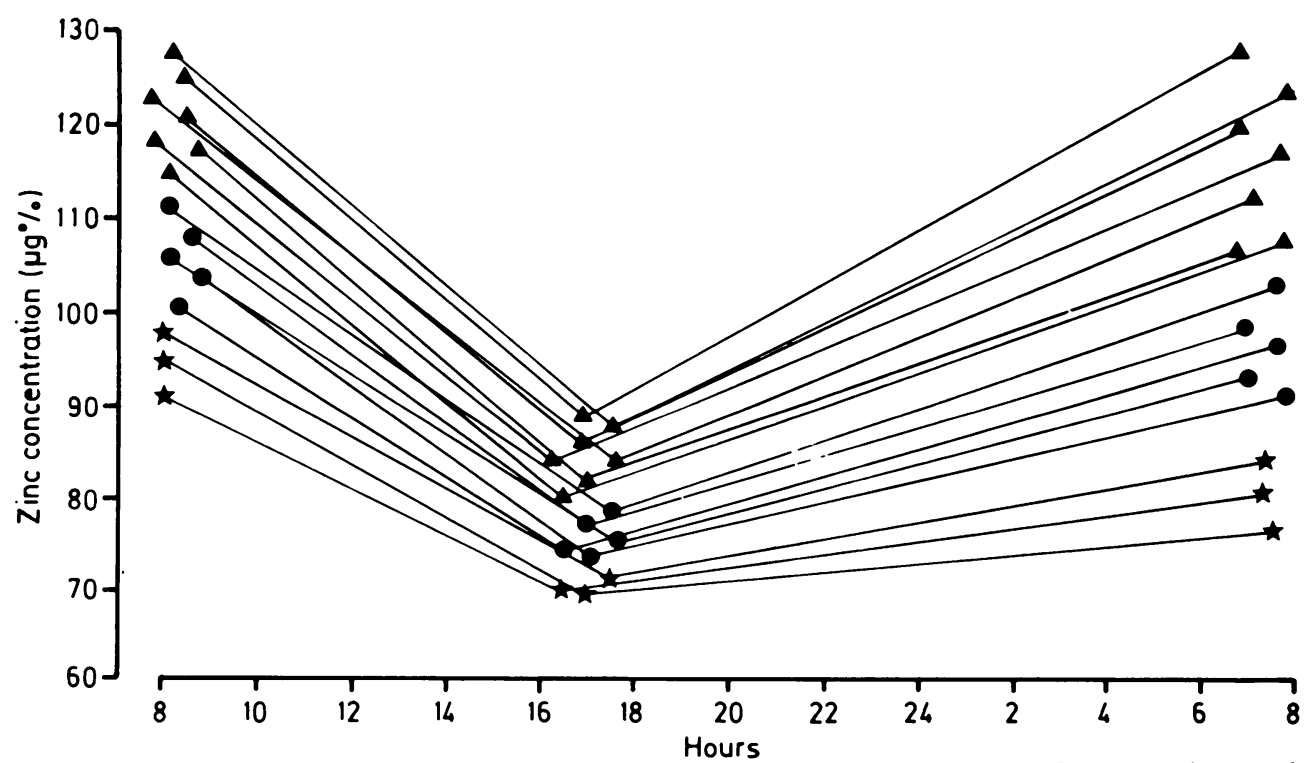

Fig 2 Effect of intravenous infusion of desferrioxamine on serum zinc concentrations. Patients with normal amplitude on electroretinography (O); patients with transitory decreased amplitude ( $\mathbf{\Delta})$; and patients with persistent decreased amplitude

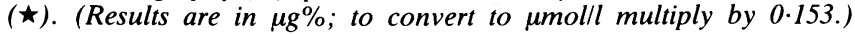


zinc pattern were observed between the three groups of subjects investigated.

The effects of desferrioxamine infusion on iron, zinc, and copper excretion are summarised in fig 3. After infusion of desferrioxamine there was a significant $(p<0.001)$ increase of mean urinary and faecal iron excretion. On average $45 \%$ of the iron was eliminated through the urine and $55 \%$ with the stools. After the infusion, faecal and urinary zinc and copper excretion were also significantly increased ( $p<0.001$ and $<0.05$, respectively). Considering all the patients together no significant correlation was observed between zinc and iron elimination both in faeces and urine.

If the patients were divided according to the abnormalities shown on their electroretinograms - that is, the first group without abnormalities, the second group with transitory alterations after intravenous infusion, and the third group with permanent abnormalities - it can be seen that the second group of patients had significantly $(p<0.05)$ higher mean urinary zinc elimination compared with the first group; there were no differences observed in iron and copper elimination. Mean faecal excretions of all the three trace elements were significantly higher in the second group $(\mathrm{p}<0 \cdot 001$ for iron and zinc; $p<0 \cdot 01$ for copper) than in the first group $(p<0.01)$. In the second group there was an inverse correlation between total zinc and iron elimination; this, however, did not reach significance. Those subjects who had persistent abnormalities on their electroretinograms had less iron, copper, and zinc excretion both in urine and faeces when compared with the other two groups.

In all patients granulocyte zinc content and

Table Effect of intravenous infusion of desferrioxamine on zinc concentrations and alkaline phosphatase activity in granulocytes

\begin{tabular}{|c|c|c|}
\hline & $\begin{array}{l}\text { Zinc } \\
\text { ( } \text { umol/g } \\
\text { protein) }\end{array}$ & $\begin{array}{l}\text { Alkaline phosphatase } \\
\text { activity } \\
(\mu M / \text { minute/g protein })\end{array}$ \\
\hline \multirow{6}{*}{$\begin{array}{l}\text { Basal* } \\
\text { At the end of the } \\
\text { infusion } \dagger \\
1 \text { month after } \\
\text { infusion* }\end{array}$} & \multicolumn{2}{|c|}{ Patients with thalassaemia } \\
\hline & $6.53(1.83)$ & $20(8 \cdot 21)$ \\
\hline & $-4 \cdot 86(1 \cdot 8)$ & $-15 \cdot 23(9 \cdot 15)$ \\
\hline & & \\
\hline & $0.41(2.27)$ & $2 \cdot 36(14 \cdot 5)$ \\
\hline & & $\begin{array}{r}\text { trols } \\
23(3 \cdot 8)\end{array}$ \\
\hline
\end{tabular}

${ }^{*}$ Results are mean (SEM).

$\nmid$ Results are mean differences from the basal value (standard errors of the differences).

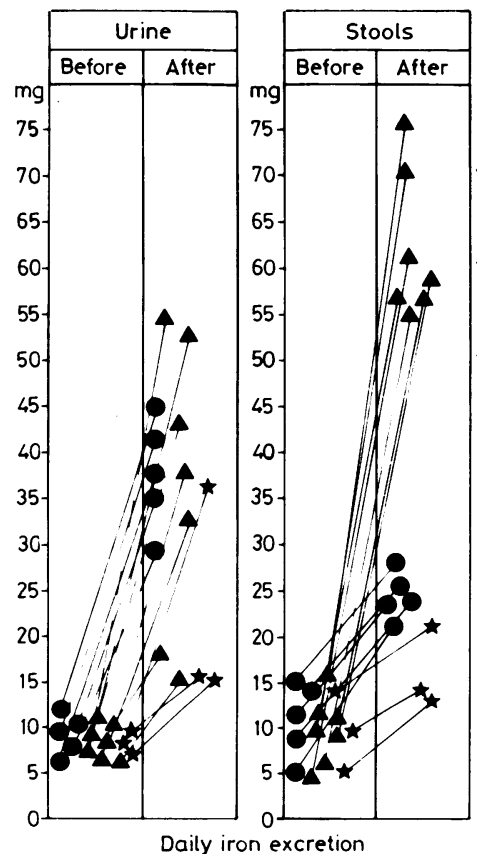

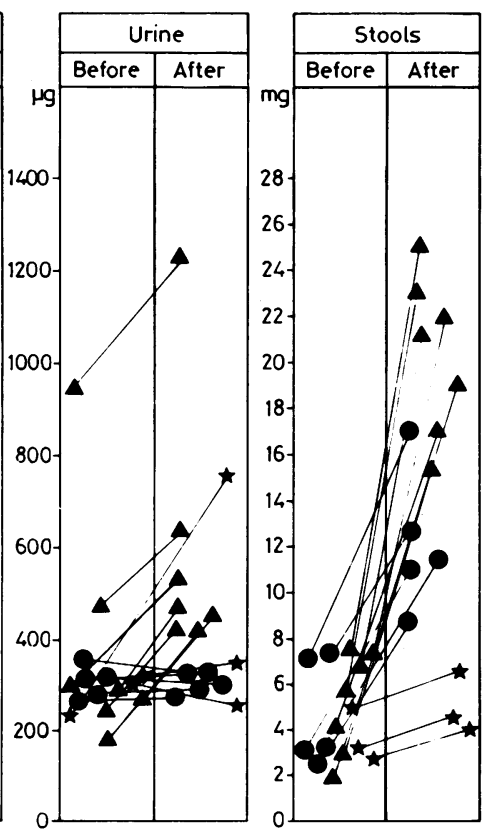

Daily zinc excretion



Daily copper excretion

Fig 3 Effect of intravenous infusion of desferrioxamine on iron, copper, and zinc excretion. Patients without abnormalities on electroretinography (O); patients with transitory alterations $(\mathbf{\Delta})$; patients with permanent abnormalities $(\star)$. Patients had baseline concentrations higher than normal because they had stopped subcutaneous administration of desferrioxamine only 24 hours previously. 
alkaline phosphatase activity were within the normal ranges at the outset of the infusion and decreased significantly $(p<0.001)$ at the end, and they returned to normal values at the determination carried out one month later (table 1). No significant differences were noted between the three groups.

\section{Discussion}

This study shows that high doses of intravenous desferrioxamine infused over a short period produce a reversible minor toxic effect on the retina, which is characterised by reduced amplitude on adapted electroretinography and defective dark adaptation. More severe retinal or optic nerve toxicity, or both, that consisted of night blindness, field defects, visual loss, loss of colour vision, and delayed visual evoked potential has been detected after intravenous or subcutaneous infusion of similar large doses of desferrioxamine for a prolonged period. ${ }^{78}$ Follow up studies in some of these patients showed evidence of evolution towards the pigmentary degeneration of the retina indicating toxicity at the level of retinal pigment epithelium. ${ }^{16}$

The fluctuations in the serum zinc concentration that are seen during infusion of desferrioxamine are probably not related to administration of the drug as they are very similar to the daily variations in serum zinc concentrations found in normal subjects (circadian rhythm). ${ }^{17}$

In this investigation large doses of intravenous desferrioxamine produced a consistent increase in iron excretion as has been found in previous studies $^{3}{ }^{11}$ but resulted also in increased elimination of zinc and copper. Intravenous desferrioxamine had more effect on the faecal loss of iron, zinc, and copper than it had on their urinary loss. We can exclude the possibility that this pattern may be due to urine contamination of faeces during collection because during the balance study the patients were in the hospital and urine and faecal collections were carefully controlled by a nurse who had been adequately instructed. Furthermore it is already known from a study carried out by Pippard et al that large doses of desferrioxamine result in an increase of faecal iron loss but have little effect on urinary elimination. ${ }^{18}$ An inverse but not significant correlation between iron and zinc excretion was observed solely in those subjects with transient abnormalities on electroretinography.

Increased copper and zinc excretion may be explained by assuming that the rapid infusion of large doses of desferrioxamine left a certain amount of the drug non-iron chelated and thus able to chelate these trace elements. Accordingly granulocyte alkaline phosphatase activity, which is one of the best indicators of the zinc content of the organism ${ }^{19}$ decreased significantly after the infusion of desferrioxamine. We cannot exclude, however, that at least partially, the decrease of leukocyte alkaline phosphatase activity may be caused by a possible interference of residual desferrioxamine in the assay of this zinc dependent enzyme.

The depletion of iron, zinc, and copper may be related to the retinal abnormalities. Experimental and clinical evidence indicate the importance of zinc in the maintenance of normal visual function. ${ }^{1920}$ First of all the highest concentration of zinc and several zinc-containing enzymes are present in the retinal epithelium. ${ }^{19} 20$ Zinc deficiency in rats produces accumulation of osmiophilic inclusion bodies containing vitamin A derivatives and degeneration of the photoreceptors outer segments. ${ }^{21}$ Optic atrophy has been described in acquired zinc deficiency due to malabsorption as well as in acrodermatitis enteropathica. ${ }^{22}$ Defective dark adaptation responsive to zinc treatment has been reported in sickle cell anaemia patients in whom leukocyte zinc concentration was low. ${ }^{19-23}$ Several drugs, notably di-iodohydroxyquinoline and penicillamine, which produce toxic optic neuropathies are also potent metal chelators. ${ }^{22}$ Abnormalities of zinc metabolism have been described also in retinitis pigmentosa. ${ }^{24}$ There are several mechanisms whereby zinc deficiency may produce deleterious effects on the retinal pigment epithelium. Zinc by decreasing alcohol dehydrogenase enzyme activity may in turn produce an increased uptake of vitamin A. ${ }^{21}$ The resulting accumulation of retinal and its esters may cause release of lysosomal enzymes. ${ }^{21}$ Zinc deficiency also enhances lipid peroxidation and impairs the metabolism of amino acids, nucleic acids, and proteins. ${ }^{19-21}$ Although our data have not established a clear relation between zinc deficiency and ocular abnormalities, they suggest, however, that zinc depletion induced by desferrioxamine in the retinal pigment epithelium may have played a part in producing the transient abnormalities that we have seen on electroretinography.

Blake et al, who studied a patient with retinal toxicity induced by desferrioxamine, also found abnormalities in the loosely bound iron and copper content of the cerebrospinal fluid. ${ }^{25}$ Copper and iron complexes may stimulate an autocatalytic process of lipid peroxidation and might therefore be responsible for retinal abnormalities in patients treated with desferrioxamine. ${ }^{26}$

Desferrioxamine acts on a labile iron pool, which is presumably intermediate in the interchange of iron molecules between storage and transport forms.$^{27}$ Acute iron depletion of this pool may have a negative effect on the iron dependent enzymes and 
help cause the production of retinal anomalies. We have excluded the possibility that ocular abnormalities in our patients were related to a diabetic or prediabetic condition via the disruption of the integrity of the blood-retinal barrier, as has been proposed, ${ }^{28}$ because none of our patients had a reduced glucose tolerance (data not shown).

A limited number (three out of 15) of the patients investigated showed persistent abnormalities on electroretinography. Because it is difficult to assess the compliance to treatment we do not know whether these patients differed from those with transient abnormalities in the amount of desferrioxamine they received by the daily subcutaneous infusion in the years preceding the trial. Those patients with persistent abnormalities did not differ, however, from those with transient modifications in the serum ferritin concentrations, the zinc content, and alkaline phosphatase activity of leukocytes, but showed lower zinc and iron excretion after intravenous infusion of desferrioxamine. This may indicate the presence of less iron accumulation and a borderline zinc reserve, which may nevertheless result in defective function of those tissues, such as the retinal epithelium, which are most sensitive to zinc depletion.

In conclusion, administration of large doses of desferrioxamine by intravenous infusion are able to produce in iron overloaded thalassaemia patients a very large iron excretion but they also induce excretion of trace elements such as copper and zinc and cause transient ocular abnormalities. For those patients treated with this regimen ophthalmological evaluation is recommended for determining early retinal toxicity induced by desferrioxamine. Further studies are needed in order to assess whether a reduction of the desferrioxamine dosage may avoid these toxic effects.

\section{References}

1 Propper RD, Cooper B, Rufo RR, et al. Continuous subcutaneous administration of desferrioxamine in patients with iron overload. N Engl J Med 1977;297:418-23.

2 Graziano JH, Markenson A, Miller DR, et al. Chelation therapy in $\beta$-thalassemia major. I. Intravenous and subcutaneous deferoxamine. J Pediatr 1978;92:648-52.

${ }^{3}$ Cohen A, Martin M, Schwartz E. Response to long term desferrioxamine therapy in thalassemia. J Pediatr 1981;99: 689-94.

${ }^{4}$ Modell B, Letzky AE, Flynn DM, Peto R, Weatherall DJ. Survival and desferrioxamine in thalassemia major. $\mathrm{Br}$ Med $J$ 1982;284:1081.

${ }^{5}$ Fargion S, Taddei MT, Gabutti V, et al. Early iron overload in $\beta$-thalassaemia major: when to start chelation therapy? Arch Dis Child 1982;57:929-33.

- De Virgiliis S, Cossu P, Toccafondi C, et al. Effect of subcutaneous desferrioxamine on iron balance in young thalassemia major patients. Am J Pediatr Hematol Oncol 1983;5:73-7.

7 Davies SC, Marcus RE, Hungerford JL, Miller MH, Arden GB, Huehns ER. Ocular toxicity of high dose intravenous desferrioxamine. Lancet 1983;ii:181-4.
${ }^{8}$ De Virgiliis S, Frau F, Sanna G, et al. Iron elimination following intravenous desferrioxamine infusion in patients with thalassemia major. European Paediatric Haematoly/Oncology 1985;2: 47-8.

9 Olivieri NF, Buncic JR, Chew E, et al. Visual and auditory neurotoxicity in patients receiving subcutaneous deferoxamine infusions. N Engl J Med 1986;314:869-73.

10 Arden GB. Desferrioxamine administered intravenously by infusion causes a reduction in the electroretinogram in rabbits anaesthetized with urethane. Hum Toxicol 1986;5:229-36.

11 Zaino EC. Desferrioxamine and trace metal excretion in chelation therapy in chronic iron overload. In: Zaino EC, Roberts RH, eds. Chelation and chronic iron overload. New York: Ciba Medical Horizons Symposium, 1977:95-107.

12 Babel JM, Stangos M, Korol S, Spiritus M. Ocular electrophysiology. Stuttgart: G Thiene Publishers, 1977:34-5.

13 Auerbach E. The human electroretinogram in the light and during dark adaptation. Doc Ophthalmol 1967;22:1-4.

14 It-Koon T, Moss DW. The estimation of intestinal alkaline phosphatase in human blood serum. Clin Chim Acta 1969;25: 177-9.

15 Boyum A. A one stage procedure for isolation of granulocytes and lymphocytes from human blood. Scand J Clin Lab Invest 1968;97(suppl 21):51-3.

${ }^{16}$ Lakhanpal V, Schocket SS, Jiji R. Deferoxamine (Desferal) induced toxic retinal pigmentary degeneration and presumed optic neuropathy. Ophthalmology 1984;91:443-51.

17 Markowitz ME, Rosen JF, Mizruchi M. Circandian variations in serum zinc $(\mathrm{Zn})$ concentrations: correlation with blood ionized calcium, serum total calcium and phosphate in humans. Am J Clin Nutr 1985;41:689-96.

${ }_{18}$ Pippard MJ, Callender ST, Finch CA. Ferrioxamine excretion in iron-loaded man. Blood 1982;60:288-94.

19 Prasad AS. Clinical, biochemical and nutritional spectrum of zinc deficiency in human subjects: an update. Nut Rev 1983;41:197-208.

${ }^{20}$ Karciogluo ZA. Zinc in the eye. Surv Ophthalmol 1982;27: 114-22.

${ }^{21}$ Leure-dePree AE, McClain CJ. The effect of severe zinc deficiency on the morphology of the rat retinal pigment epithelium. Invest Ophthalmol Vis Sci 1982;23:425-34.

22 Wong Jr EK, Leopold IH. Zinc deficiency and visual dysfunction. Metabolic and Pediatric Ophthalmology 1979;3:1-4.

${ }^{23}$ Warth JA, Prasad AS, Zwas F, Frank RN. Abnormal dark adaptation in sickle cell anemia. J Lab Clin Med 1981;98: 189-94.

${ }^{24}$ Silverstone BZ, N.Bursen D, Seelenfreund MH. Plasma zinc levels in high myopia and retinitis pigmentosa. Medical and Pediatric Ophthalmology 1981;5:187-90.

${ }^{25}$ Blake DR, Winyard P, Lunec J, et al. Cerebral and ocular toxicity induced by desferrioxamine. $Q J$ Med 1985;56:345-55.

26 Gutteridge JMC. Fluorescent products of phospholipid peroxidation: Formation and inhibition in model systems. In: Armstrong D, Koppang N, Rider JA, eds. Ceroid lipofuscinosis (Batten's disease). Amsterdam: Elsevier, Biomedical Press, 1982:351-64.

${ }^{27}$ Laub R, Schneider YJ, Octave JN, Trouet A, Crichton RR. Cellular pharmacology of deferrioxamine $\mathrm{B}$ and derivatives in cultured rat hepatocytes in relation to iron mobilization. Biochem Pharmacol 1985;34:1175-83.

28 Arden GB, Wonke B, Kennedy C, Huehns ER. Ocular changes in patients undergoing long-term desferrioxamine treatment. Br J Ophthalmol 1984;68:873-77.

This work was partially financed by the Assessorato lgiene e Sanita'-Regione Sardegna.

Correspondence to Professor A Cao, Instituto di Clinica c Biologia dell' Eta' Evolutiva, Universita' Studi Cagliari, Via Jenner $s / n$, I-09100 Cagliari, Sardinia, Italy.

Accepted 16 September 1987 